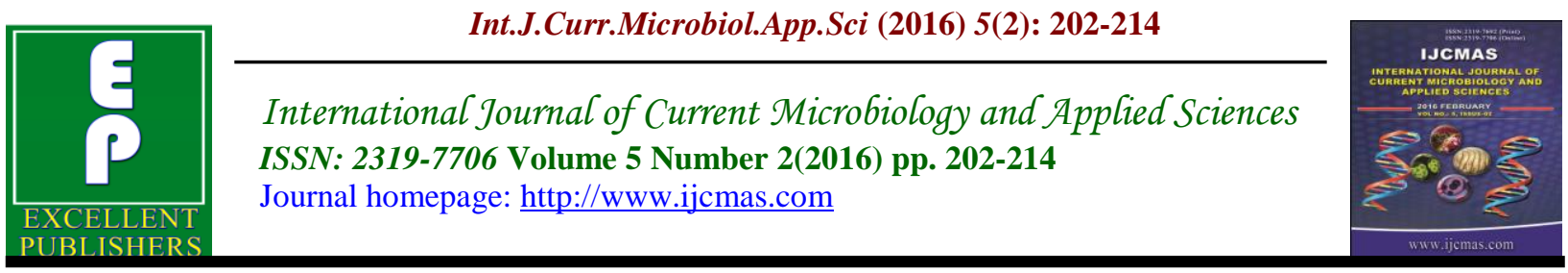

Original Research Article doi: http://dx.doi.org/10.20546/ijcmas.2016.502.023

\title{
An interventional study for reducing Ventilator Associated Pneumonia in Surgical Intensive Care Unit, Zagazig University Hospitals
}

\author{
Amany Rashad Abo Elseoud ${ }^{1}$, Mona Mostafa AboSerea ${ }^{1}$, \\ Ghada Mohammed Abed El Razek ${ }^{2}$ and Safa Abdul Monaem Hussein ${ }^{1} *$ \\ ${ }^{1}$ Departments of Public Health and Ansethiology and Intensive Care, Egypt \\ ${ }^{2}$ Faculty of Medicine, Zagazig University, Egypt \\ *Corresponding author
}

\section{Keywords \\ Mechanical ventilator, Ventilator Associated Pneumonia , Intensive care unit.}

\begin{tabular}{l}
\hline Article Info \\
\hline Accepted: \\
14 January 2016 \\
Available Online: \\
10, February 2016
\end{tabular}

Ventilator-associated pneumonia (VAP) is considered as a leading cause of infection related mortality and morbidity in intensive care units (ICUs) together with increasing the length of ICU stay and rising the cost of antibiotic treatment of VAP especially in developing coutries. Education of ICU healthcare providers is widely viewed as a fundamental measure in reducing VAP. So, this study aimed to improve health outcome of patients on mechanical ventilation through decreasing ventilator associated pneumonia in surgical intensive care unit at Zagazig University Hospitals through the following 1-To assess knowledge of health care providers in surgical intensive care units about the guidelines recommended by Association for Professionals in Infection Control \& Epidemiology (APIC) to decrease ventilator associated pneumonia before and after health education intervention. 2- To calculate incidence rate of ventilator associated pneumonia in surgical intensive care unit over a period of six months before and six months after intervention. 3-To estimate length of ICU stay of ventilator associated pneumonia patients in surgical intensive care unit over a period of six months before and six months after intervention. 4-To estimate costs of antibiotic treatment of VAP in surgical intensive care unit over a period of six months before and six months after intervention a quazi experimental (pre-post test) study was conducted in surgical ICU at Zagazig University Hospital during the years 2014-2015. All health care providers in this unit (10 physicians \& 29 nurses) were included in the study. All Patients on mechanical ventilation were consecutively enrolled in during the period of the pre and post intervention phases (82 \&84) respectively. Two constructed questionnaires were answered to assess their knowledge about HAIs and VAP prevention measures before and after the intervention. The VAP incidence rate, length of stay (LOS) and cost of antibiotic treatment were calculated during each of pre and post intervention phases. The educational program involved physicians and nurses and included a message covering the guidelines recommended by Association for Professionals in Infection Control and Epidemiology (APIC). In the $1^{\text {st }}$ phase, $31.7 \%$ of ventilated patients developed VAP while in the post intervention phase after the intervention, only $16.7 \%$ of patients were diagnosed as VAP cases with a statistically significant difference. The VAP incidence rate dropped by $25.7 \%$ from $29.5 \mathrm{VAP}$ cases/1000 vent. days in phase 1 to 21.5 in phase 2. As regards to the LOS and the cost of antibiotic treatment of VAP, no statistically significant difference is found between both phases The effect of educational intervention on total knowledge improvement of physicians, knowledge about hospital acquired infection and VAP prevention measures improved significantly while knowledge of nurses improved significantly regarding HAI, VAP and VAP prevention measures. this study revealed that a relatively simple education program for implementation of guidelines recommended by APIC reduced the incidence rate of ventilator associated pneumonia in intensive care unit. 1.Continuous health education and training of ICU healthcare personnel regarding the knowledge, attitude and practice towards general infection control guidelines in the intensive care units, ventilator associated pneumonia (VAP) and the periodically updated evidence based guidelines for its prevention.2. Reevaluation of the intensive care unit policy to adopt the APIC prevention guidelines of VAP and other evidence based bundles for the prevention of different hospital acquired infections in the ICU.3. Standardize the case definition and the management protocol of VAP in all intensive care units.4. Enhancing appropriate use of antimicrobial treatment in the ICU setting to reduce antibiotic resistance and cost and to improve the patient's clinical response.5. Conduct more specific economic studies with longer follow up periods for evaluation of the economic cost and impact of VAP.6. Proper and full recording of different aspects of Zagazig hospital's costs for each department to facilitate economic or financial study analysis. 


\section{Introduction}

Ventilator-associated pneumonia (VAP) is a pneumonia where the patient is on mechanical ventilation for $>2$ calendar days on the date of event, with day of ventilator placement being Day 1, and the ventilator was in place on the date of event or the day before (1). Locally occurring, VAP incidence rate in the surgical ICU at Zagazig university hospital at Al Sharqia governorate was estimated to be as high as 64.5 per 1000 ventilator days (2). VAP is associated with increases in death rates, length of stay and health care costs (3). Altough being one of the biggest challenges in the critical care team, the prevention of vap shows promising results, it improves the survival rate, decease both days of antibiotic use and days in the critical care unit (5). All ICU healthcare providers should be educated about and take an active role in VAP prevention (6).

\section{Subjects and Method}

Study type, setting and time: A quazi experimental (pre-post test) study was conducted in the surgical intensive care unit (SICU) at Zagazig University Hospital during the years 2014-2015.

All health care providers in that SICU were included (10 physicians and 29 nurses).

\section{Study Population}

All Patients on mechanical ventilation in the SICU were consecutively enrolled in during the period of study $(6$ months before intervention and 6 months after intervention). That is to say; 82 patients before intervention and 84 patients after intervention were included in the study. Inclusion criteria of patients: all the surgical ICU patients ventilated for more than two
(2) days throughout the duration of pre intervention and post intervention phases of the study were included. Exclusion criteria: 1- Non ventilated surgical ICU patients. 2Surgical ICU patients, ventilated for less than two (2) days.

The study was carried out through 3 phases

The first and the third phases included the following: 1-An active surveillance for calculating incidence rate of ventilator associated pneumonia (VAP) as such: number of ventilator associated pneumonia cases/ number of ventilator days*1000. 2Collecting data about VAP patients including: age, sex, underlying condition, total number of ventilator days, antimicrobial therapy prior to VAP onset, organism isolated from culture of tracheal aspirate specimen. 3- Assessment of knowledge of health care providers (physicians and nurses) about hospital acquired infections, VAP and guidelines recommended to prevent VAP. Two constructed questionnaires, English for physicians and Arabic for nurses were modified and revised by public health professors and they cover the following items:

Sociodemographic characteristics of health care providers in the studied ICU age, qualification, number of years of experience and previous attendance of infection control courses).

Knowledge about hospital acquired infection; what is the definition, risk factors, causes, sources, route of transmission and goal of infection control in the ICU.

Knowledge about ventilator associated pneumonia; such as definition and complications. 
Knowledge about guidelines recommended by APICto decrease ventilator associated pneumonia.

Calculation of length of ICU stay of all VAP patients in each of the pre and post intervention phases from patient records including time of admission and discharge, referral to other department or death.

Calculation of costs of antibiotic treatment of VAP in each of the pre and post intervention phases using official records obtained from cost administration department and pharmacy records.

In the second phase, Guidelines recommended by Association for Professionals in Infection Control \& Epidemiology (APIC) were disseminated in intensive care unit as: Booklets, Posters, lectures (power point) and open discussion.

An extra information was adopted in the message through adding:

World Health Organization (WHO) recommended hand washing and hand rub procedures

Detailed oral care including: oral swab and teeth brushing

\section{Data Management was as follows}

The VAP incidence rate was calculated as such: number of ventilator associated pneumonia cases/ number of ventilator days*1000.

Relative risk of no intervention was calculated as =incidence of VAP among those with no intervention\ incidence of VAP among those with intervention.

Percentage of change was used to describe the $\%$ of improvement in VAP incidence rate after the intervention calculated as such $=$ pre intervention-post intervention $\backslash$ pre intervention* 100

Unsatisfactory knowledge was considered $\leq$ the median $(50 \%)$ of total correct knowledge score and scores $>$ the median $(50 \%)$ were considered as satisfactory knowledge.

\section{Statistical Analysis}

The collected data were analyzed by computer using a data base software program, Statistical Package of Social Services version 16and Epidemiological Information Package (EPi-Info) version 6.04. Qualitative data were represented as frequencies \& percentages while quantitative data were represented by mean and standard deviation. Suitable tests of significance were used to detect relations \& differences between different qualitative or quantitative variables. The results were considered statistically significant when the significant probability was less than or equal to $(\mathrm{p} \leq$ $0.05)$.

\section{Administrative Design}

An official permission was obtained from head manager of the New Surgery Hospital at Faculty of medicine and the head manager of surgical intensive care unit.

The approval of the Institutional Research Board (IRB) was obtained before the start of the study.

\section{Ethical Consideration}

1. The new surgery hospital at Faculty of medicine and surgical intensive care unit were informed about the nature and steps of the study.

2. The study participants (physicians and nurses) were informed about the nature and 
the purpose of the study and an informed consent were taken before interview and were not exposed to any harm or risk.

\section{All participants' data were confidential.}

\section{Results and Discussion}

Concerning the mechanically ventilated patients in the surgical ICU, they were 82 patients before \& 84 patients after intervention. Table (1) showed age, sex and underlying health problems of those patients. Following our intervention, the VAP incidence rate significantly dropped by $25.7 \%$ from 29.5 to $21.5 \mathrm{VAP}$ cases $/ 1000$ vent. days, the relative $\operatorname{risk}(\mathrm{RR})$ of no intervention $=1.37($ Table 2$)$

Table (3) showed VAP patients age, sex and underlying health problems. No statistically significant difference is found between the underlying health problem, Antibiotic intake before VAP development or the no. of ventilator days ( $\mathrm{p}$ value $>0.05$ ).Also, the duration of ventilation is mostly $>30 \mathrm{~d}$ in phase 1 and (10-20ds) in phase 2. Regarding the type of organisms isolated from sputum culture of VAP patients, Klebsiella and Acetinobacter were the most frequently isolated organisms in both phases without significant difference( Table4).

As regards to the LOS and the cost of antibiotic treatment of VAP, no statistically significant difference is found between both phases (Table5). The majority of physicians in the surgical ICU (70.0\%) were of younger (20- $<30$ years) age group, had $\mathrm{MBBCH}$ and they had experience years less than 12 months. Only half of them attended infection control courses.

Assessment of the effect of the educational intervention among the physicians showed that the total knowledge about hospital acquired infection and about VAP prevention measures improved significantly between pre and post intervention phases ( $\mathrm{P}$ value $<0.05)$ while as for the total knowledge about VAP, there was no statistically significant difference between both phases ( $\mathrm{P}$ value $>0.05)$ (Figure 1$)$.

The majority of the ICU nurses $(58.6 \%)$ were at younger age group $(20-<30)$ years, had diplomate degree $(79.3 \%)$, had experience years less than 5 years $(41.4 \%)$ and did not attend of infection control courses $(58.6 \%)$.

Moreover, and regarding the effect of our educational intervention among the nurse staff of the SICU, we found statistically significant improvement of the total knowledge about hospital acquired infection, VAP and VAP prevention measures between both phases ( $\mathrm{P}$ value $<$ 0.05) (Figure 2).

In this study we were concerned with the incidence of VAP among the mechanically ventilated patients in both phases before and after health education intervention, the length of ICU stay of the VAP patients and the cost of antibiotic treatment of VAP, together with the effect of of our health education intervention on the total knowledge of physicians and nurses about HAI, VAP and VAP prevention measures.

Regarding the mechanically ventilated patients, we found in the $1^{\text {st }}$ phase, most of them were males of significantly younger age than those in the post intervention phase (table1) that could be explained by the significant decrease in number of admissions due to polytrauma in the postintervention phase which is usually associated with younger males being more active outdoors and more accident prone. 
Table.1 Frequency Distribution of some Socio Demographic and Medical Characteristics of the Studied Mechanically Ventilated Patients in both Pre and Post Intervention Phases of the Study

\begin{tabular}{|c|c|c|c|c|c|c|}
\hline \multirow{2}{*}{$\begin{array}{l}\text { Demographic } \\
\text { Character }\end{array}$} & \multicolumn{2}{|c|}{$\begin{array}{l}\text { pre intervention } \\
(n=82)\end{array}$} & \multicolumn{2}{|c|}{$\begin{array}{l}\text { post intervention } \\
(n=84)\end{array}$} & \multirow[t]{2}{*}{$\begin{array}{l}\text { Test of } \\
\text { significance }\end{array}$} & \multirow[t]{2}{*}{ P value } \\
\hline & No & $\%$ & No & $\%$ & & \\
\hline $\begin{array}{l}\text { Sex: } \\
\text { Male } \\
\text { Female } \\
\end{array}$ & $\begin{array}{l}53 \\
29\end{array}$ & $\begin{array}{l}64.6 \\
35.4\end{array}$ & $\begin{array}{l}50 \\
34 \\
\end{array}$ & $\begin{array}{l}59.6 \\
40.4 \\
\end{array}$ & $\begin{array}{l}\mathrm{X}^{2} \text { test } \\
= \\
0.460\end{array}$ & 0.498 \\
\hline $\begin{array}{l}\text { Underlying health } \\
\text { problem: } \\
\text { Postoperative } \\
\text { complication } \\
\text { Polytrauma } \\
\text { CNS } \\
\text { CVS }\end{array}$ & $\begin{array}{l}40 \\
29 \\
5 \\
8\end{array}$ & $\begin{array}{c}48.8 \\
35.4 \\
6.1 \\
9.8\end{array}$ & $\begin{array}{l}50 \\
14 \\
14 \\
6\end{array}$ & $\begin{array}{c}59.5 \\
16.7 \\
16.7 \\
7.1\end{array}$ & $\begin{array}{l}X^{2} \text { test } \\
1.929 \\
7.551 \\
4.573 \\
0.366\end{array}$ & $\begin{array}{l}0.165 \\
0.005^{*} \\
0.032^{*} \\
0.544\end{array}$ \\
\hline Age (years) : Mean \pm SD & 41.9 & & 47.7 & & Mann Whitney & $0.056^{*}$ \\
\hline
\end{tabular}

* Statistically significant at $\mathrm{P} \leq$ value

Table.2 VAP* Incidence rate among the Studied Mechanically Ventilated Patients in both Pre and Post Intervention Phases of the Study

\begin{tabular}{|c|c|c|c|c|c|c|}
\hline Item & \multirow{2}{*}{\multicolumn{2}{|c|}{\begin{tabular}{|l|}
$(\mathbf{n}=\mathbf{8 2})$ \\
882
\end{tabular}}} & \multirow{2}{*}{\multicolumn{2}{|c|}{$\begin{array}{c}\begin{array}{c}\text { post intervention } \\
(\mathbf{n}=\mathbf{8 4})\end{array} \\
651\end{array}$}} & \multirow[t]{2}{*}{$\begin{array}{l}\text { Test of } \\
\text { significance }\end{array}$} & \multirow[t]{2}{*}{ P value } \\
\hline & & & & & & \\
\hline \multirow{2}{*}{$\begin{array}{l}\text { VAP development: } \\
\text { Yes } \\
\text { No }\end{array}$} & No & $\%$ & No. & $\%$ & \multirow{2}{*}{$\begin{array}{l}X^{2} \text { test }= \\
5.132\end{array}$} & \multirow[b]{2}{*}{$0.023 *$} \\
\hline & $\begin{array}{l}26 \\
56\end{array}$ & $\begin{array}{l}31.7 \\
68.3\end{array}$ & $\begin{array}{l}14 \\
70\end{array}$ & \begin{tabular}{|l|}
16.7 \\
83.3
\end{tabular} & & \\
\hline \multirow{2}{*}{$\begin{array}{l}\text { VAP incidence rate } \\
\text { (VAP cases } / 1000 \text { vent. } \\
\text { days) }\end{array}$} & \multirow{2}{*}{\multicolumn{2}{|c|}{29.5}} & \multirow{2}{*}{\multicolumn{2}{|c|}{21.5}} & \multicolumn{2}{|l|}{ Relative risk $=1.37$} \\
\hline & & & & & $\begin{array}{l}\text { Percentage of } \\
=25.7 \%\end{array}$ & iprovement \\
\hline
\end{tabular}

Table.3 Frequency Distribution of some Sociodemographic Characteristics of the Studied Ventilator Associated Pneumonia Patients in both Phases

\begin{tabular}{|c|c|c|c|c|c|c|}
\hline \multirow{2}{*}{$\begin{array}{l}\text { Sociodemographic } \\
\text { characteristics }\end{array}$} & \multicolumn{2}{|c|}{$\begin{array}{l}\text { pre intervention } \\
(\mathrm{n}=\mathbf{2 6})\end{array}$} & \multicolumn{2}{|c|}{$\begin{array}{l}\text { post intervention } \\
(\mathrm{n}=14)\end{array}$} & \multirow[t]{2}{*}{$\begin{array}{ll}\text { Test } & \text { of } \\
\text { significance }\end{array}$} & \multirow[t]{2}{*}{ P value } \\
\hline & No & $\%$ & No. & $\%$ & & \\
\hline $\begin{array}{l}\text { Sex: } \\
\text { Male } \\
\text { Female }\end{array}$ & $\begin{array}{c}18 \\
8\end{array}$ & $\begin{array}{l}69.2 \\
30.8\end{array}$ & $\begin{array}{l}9 \\
5\end{array}$ & $\begin{array}{l}64.3 \\
35.7\end{array}$ & $\begin{array}{l}X^{2} \text { test } \\
0.101\end{array}$ & 0.750 \\
\hline Age (years): Mean \pm SD & \multicolumn{2}{|c|}{$34.6 \pm 17.8$} & \multicolumn{2}{|c|}{$37.7 \pm 18.1$} & Mann Whitney & 0.723 \\
\hline
\end{tabular}


Table.4 Frequency Distribution of some Medical Characteristics of the Studied VAP Patients in Pre and Post Intervention Phases

\begin{tabular}{|c|c|c|c|c|c|c|}
\hline \multirow[t]{2}{*}{ Item } & \multicolumn{2}{|c|}{\begin{tabular}{|l|} 
pre intervention \\
$(\mathrm{n}=26)$
\end{tabular}} & \multicolumn{2}{|c|}{\begin{tabular}{|ll}
$\begin{array}{l}\text { post } \\
(n=14)\end{array}$ & intervention \\
\end{tabular}} & \multirow[t]{2}{*}{ Test of significance } & \multirow[t]{2}{*}{ P value } \\
\hline & No & $\%$ & No. & $\%$ & & \\
\hline $\begin{array}{l}\text { Underlying health problem: } \\
\text { Postoperative complications } \\
\text { Polytrauma } \\
\text { CNS } \\
\text { CVS } \\
\end{array}$ & \begin{tabular}{|l}
6 \\
14 \\
1 \\
5 \\
\end{tabular} & \begin{tabular}{|l}
23.1 \\
53.8 \\
3.8 \\
19.2 \\
\end{tabular} & $\begin{array}{l}4 \\
7 \\
2 \\
1 \\
1\end{array}$ & $\begin{array}{l}28.6 \\
50.0 \\
14.3 \\
7.1 \\
\end{array}$ & $\begin{array}{l}\text { Fischer exact } \\
X^{2} \text { test }=0.053 \\
\text { Fischer exact } \\
\text { Fischer exact }\end{array}$ & $\begin{array}{l}0.983 \\
0.816 \\
0.550 \\
0.599 \\
\end{array}$ \\
\hline $\begin{array}{l}\text { Antibiotic intake before VAP: } \\
\text { Yes } \\
\text { No }\end{array}$ & $\begin{array}{l}21 \\
5\end{array}$ & $\begin{array}{l}80.8 \\
19.2\end{array}$ & $\begin{array}{l}14 \\
0\end{array}$ & $\begin{array}{l}100 \\
0.0\end{array}$ & Fischer exact test & 0.199 \\
\hline $\begin{array}{l}\text { No. of ventilator days: } \\
<10 \\
10- \\
20- \\
30+ \\
\end{array}$ & $\begin{array}{l}3 \\
8 \\
6 \\
9\end{array}$ & \begin{tabular}{|l}
11.5 \\
30.8 \\
23.1 \\
34.6 \\
\end{tabular} & $\begin{array}{l}1 \\
9 \\
3 \\
1\end{array}$ & \begin{tabular}{|l|}
7.1 \\
64.3 \\
21.4 \\
7.1 \\
\end{tabular} & $\begin{array}{c}\mathrm{X}^{2} \text { test for trend } \\
= \\
2.58\end{array}$ & 0.112 \\
\hline $\begin{array}{l}\text { Isolated organisms: } \\
\text { Klebsiella pneumoni } \\
\text { Acetinobacter } \\
\text { Other }\end{array}$ & $\begin{array}{l}17 \\
5 \\
13\end{array}$ & $\begin{array}{l}65.4 \\
19.2 \\
50.0\end{array}$ & $\begin{array}{l}5 \\
6 \\
7\end{array}$ & $\begin{array}{l}35.7 \\
42.6 \\
49.9\end{array}$ & $\begin{array}{l}X^{2} \text { test }=3.237 \\
\text { Fischer exact } \\
X^{2} \text { test }=0.015\end{array}$ & $\begin{array}{l}0.072 \\
0.552 \\
0.901\end{array}$ \\
\hline
\end{tabular}

Table.5 Length of ICU stay (LOS) and Cost of Antibiotic Treatment of (VAP) among the Studied Ventilator Associated Pneumonia (VAP) Patients in both Phases

\begin{tabular}{|l|l|l|l|l|}
\hline Item & $\begin{array}{l}\text { pre intervention } \\
(\mathbf{n = 2 6})\end{array}$ & $\begin{array}{l}\text { post intervention } \\
(\mathbf{n = 1 4 )}\end{array}$ & $\begin{array}{l}\text { Test } \\
\text { significance }\end{array}$ & $\begin{array}{l}\text { P } \\
\text { value }\end{array}$ \\
\hline $\begin{array}{l}\text { Length of ICU stay (days): } \\
\text { Mean } \pm \text { SD } \\
\text { Range }\end{array}$ & $35.3 \pm 21.7$ & $30.6 \pm 14.1$ & & \\
& $6-85$ & $14-60$ & $\begin{array}{l}\text { Mann } \\
\text { Whitney }\end{array}$ & 0.644 \\
\hline $\begin{array}{l}\text { Cost of antibiotics (L.E) : } \\
\text { Mean } \pm \text { SD }\end{array}$ & $6461.6 \pm 3485.5$ & $6715.8 \pm 2788.4$ & Mann & \\
& & & Whitney & 0.856 \\
\hline
\end{tabular}

Fig.1 Effect of Health Education Intervention on the Total Satisfactory Knowledge of HAI, VAP and VAP Prevention Measures among the Physician Staff

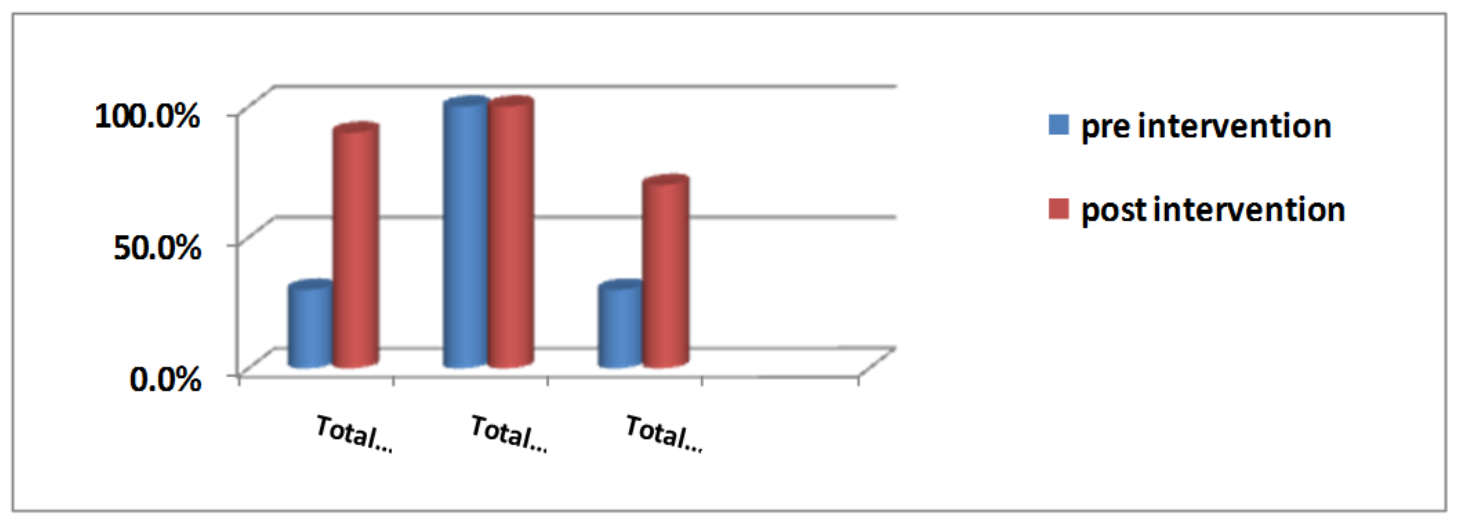


Fig.2 Effect of Health Education Intervention on the Total Satisfactory Knowledge of HAI, VAP and VAP Prevention Measures among Nurse Staff

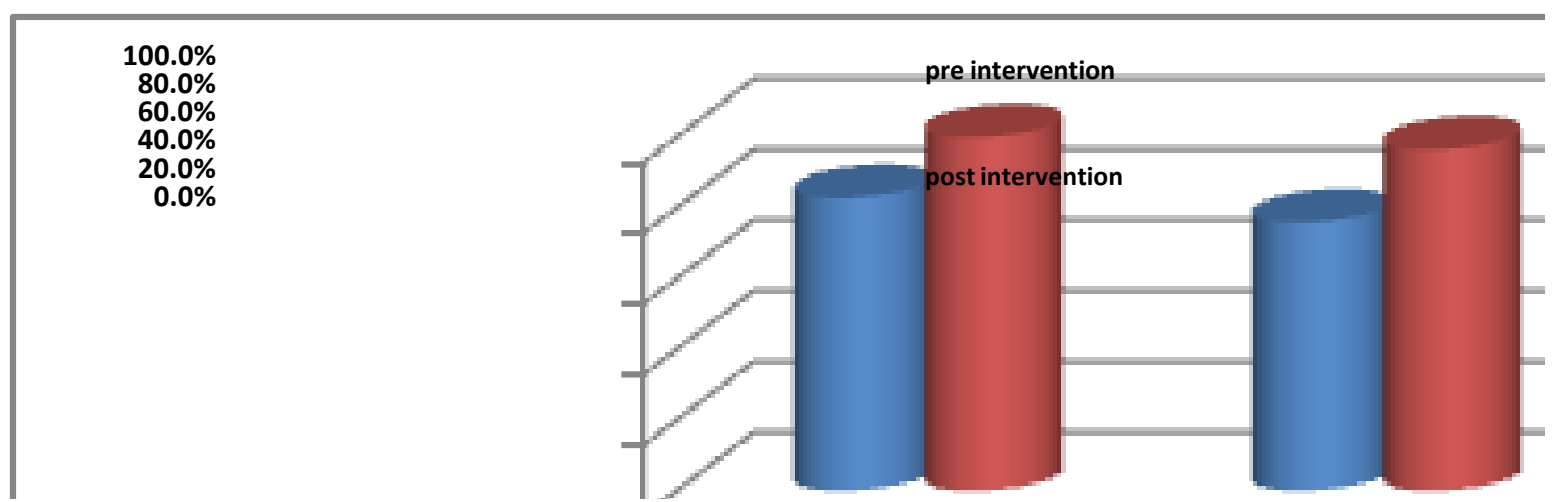

Regarding the distribution of underlying health problems, the majority in both phases were of postoperative complications and polytrauma (table 1), in contrast to Apisarnthanarak et al. (2007) \& Hawe et al.(2009) who stated that the majority of admissions in their studies were due to medical causes. This could be explained by the policy of the surgical ICU of our study that gives the highest priority of admission for postoperative cases together with major trauma patients, while other ICUs in our hospitals basically accept other medical emergencies

The VAP incidence rate in the pre intervention phase was29.5 VAP cases/1000 vent.days (Table 2) which was nearly equal to that of El-Kholy et al. (2012)in Cairo (30.3 cases per 1000 ventilator days), less than that study results from Argentina by Rosenthal (2006) (35.5 cases per 1000 ventilator days) and higher than that of the study held in USA by Zack (2002)(12.6 cases per 1000 ventilator days) and that study carried out by Gatell et al. (2012)in Spain (9.9 cases per 1000 ventilator days)

Following our intervention, the VAP incidence rate improved by $25.7 \%$ (Table 2) that could be attributed to the effectiveness of our educational intervention with a relative risk of no intervention $=1.4$ (Table 2). In a line with our results, Babcock, et al.(2004)declared that the VAP incidence rate in the 18 months following their intervention dropped but with a higher percentage of improvement $(46.0 \%)$ that could reflect higher effectiveness of their intervention, higher practical compliance and adherence of care providers to the guidelines in the educational message or more strict institutional evaluation policy of providers' performance regarding VAP preventive guidelines and also might be attributed to the longer duration of post intervention phase (18 months) providing an opportunity for the intervention outputs to be more evident.

As for VAP patients, those in the $1^{\text {st }}$ phase were mostly males, younger than those in the post intervention phase with no statistically significant difference (table3). Fortunately, this non significant difference between pre and post intervention phases regarding the age and sex provided some sort of matching between the samples of VAP patients before and after the intervention allowing for the study of effect of other factors on the development of VAP.

Regarding the underlying health problems of the VAP patients in our study, the majority 
of them in both pre and the post intervention phases suffered from polytrauma $(53.8 \%$ and $50 \%$ ) followed by postoperative complications( $23.1 \%, 28.6 \%$ ) respectively with no statistically significant difference (Table 4). This was similar to El Nakera et al. (2012)in the same ICU in Zagazig \& Baldwin and O'Neill (2015) in Germany while contradicted with Apostolopoulou et al. (2013)who found that the majority of patients were admitted due to medical diseases followed by surgical causes (32.9\%) which could be attributed to variation in the ICU admission policies among different studies.

Most of VAP cases in both phases received antibiotic therapy prior to the development of VAP $(80.8 \%, 100.0 \%)$ respectively with no significant difference (Table 4) which was similar to Apisarnthanarak et al.(2007)(13). Actually, the empirical prescription of antibiotics for the patients in our ICU was found to be mainly attributed to the physicians' attitude of lacking the trust in the effectiveness of infection control measures of the ICU together with the continuous availability of intravenous line of the patients facilitating the introduction of systemic antibiotics However, it is known that prior use of antibiotics is considered as a risk factor for HAIs (22). Moreover, a history of antibiotic use prior to the onset of ventilator-associated pneumonia (VAP) increases the probability of infection with multidrug-resistant (MDR) pathogens.(23).

Regarding the number of ventilation days of the VAP patients, the majority of them in the pre intervention phase $(34.6 \%)$ were ventilated for more than 30 days and the majority of patients $(64.3 \%)$ were ventilated for a duration of 10-20 days in the post intervention phase with no significant difference between them (Table 4), the same as the study in Alexandria by Elmenshawy et al. (2014)(24)
Concerning microorganisms isolated from sputum culture of VAP patients, Klebsiella and Acetinobacter formed the majority in phase $1(65.4 \%, 19.2 \%)$ respectively, while in $2^{\text {nd }}$ phase, Acetinobacter, Klebsiella and Staphylococcus represented the most frequently isolated organisms (42.9\%, $35.7 \%$ and $28.6 \%$ ) respectively with no significant difference(Table 4). Similarly, Danchaivijitr et al. (2005)found Acenitobacter baumannii to be the most prevalent VAP-associated microorganisms in both phases $(30.0 \%, 24.4 \%)$ with no statistically significant difference. Differently, Babcock, et al. (2004)from USA documented that Pseudomonas aeruginosa was the most commonly identified organism associated with VAP (22.3\% pre intervention vs $23 \%$ post intervention) followed by Staphylococcus aureus. Also, the systematic review of VAP in developing countries by Arabi et al. (2008) (26)concluded that the most frequently isolated organisms in VAP studies were Pseudomonas aeruginosa, Acenitobacter followed by Candida species.

Although the mean length of ICU stay (LOS) of the VAP patients decreased from $35.3 \pm 21.7$ days to $27.3 \pm 11.9$ days following our intervention, yet there was no statistically significant difference between them (Table 5). This was in disagreement with Hawe et al. (2009)from UK who stated that the median LOS increased from 4.5 days in phase 1 to 5 days in phase 2 with no statistically significant difference $(\mathrm{P}>0.05)$ and Elmenshawy et al. (2014)who found that the ICU stay didn't change before and after the intervention.

The base line LOS was longer than Madani et al., (2009)from Moracco who reported the mean LOS to be 10.6 days.

Calculated by the Egyptian pound currency, 
the cost of antibiotic treatment of ventilator associated pneumonia among VAP patients slightly increased from the $1^{\text {st }}$ phase $(6324.4$ $\pm 3921.9)$ to $(6715.8 \pm 2788.4)$ L.E in the post intervention phase without significant difference between both phases .As stated by some ICU consultants, the choice of antibiotic prescription in case of VAP diagnosis is usually affected by other associated infections which largely vary regarding the severity and sensitivity to antibiotics. Moreover, this could be explained by the increasing trend of prescription of more recent and expensive antibiotic medications to manage the increase in antibiotic resistance in different health care facilities, including the intensive care units in the present study. Actually, we have faced difficulties in obtaining the full precise data about antibiotic costs, being incomplete and lacking the formal format reflecting the need for more specialized economic studies in the ICUs. In disagreement with our findings, Apisarnthanarak et al.(2007) (13)calculated the monthly antibiotic cost for VAP treatment per United States (US) dollars to be $2901 \pm 510$ dollars in phase 1 which slightly decreased in the postintervention phase to $2884 \pm 521$ dollars with no statistically significant difference (Table 5). In addition, Joiner et al. (1996)who prevented 18 cases of lower respiratory tract infection after intervention, declared a cost savings of $\$ 126,000$ within one year duration.

According to our study, Figure (1) illustrates that only $(30.0 \%)$ of the physicians had adequate knowledge about hospital acquired infections in the pre intervention phase which calls for the urgent enforcement and auditing of the educational activities about basics of infection control to ensure the adequate attendance and participation of the working physician staff. Following our intervention, it significantly improved to $(90.0 \%)$ especially regarding the definition and sources of HAIs. This was in accordance with Bayomi (2012) while contradicted El Nemr et al. (2013) (30), both studies held in Zagazig University Hospital. Also, the total correct knowledge about VAP prevention measures increased from $30.0 \%$ before the intervention to $70.0 \%$ after the intervention with a statistically significant difference mainly regarding :the need to remove condensate from ventilatory circuits before repositioning the patient and avoiding long term enteral feeding in ventilated patient whenever possible. This improvement matched the results of Zack (2002) Apisarnthanarak et al.(2007) Jansson et al.(2013)(31) Elmenshawy et al. (2014) (24). No significant correlation was found between the sociodemographic \& qualification characteristics of physicians and the percentage of improvement in the total knowledge of them.

Surprisngly, Although most of nurses did not attend IC courses yet, it was found that $(82.8 \%)$ of them had adequate knowledge about hospital acquired infections in the pre intervention phase which significantly increased to $(100.0 \%)$ (Figure2). This finding matched Galal et al. (2014) while was different from Eskander et al. (2013) who concluded that approximately two thirds $(63.6 \%)$ of them had unsatisfactory knowledge.The same was found regarding total correct knowledge about VAP and that agreed with Tolentino-DelosReyes et al. (2007)

Nevertheless, correct knowledge about VAP prevention measures was low $(51.7 \%)$ which could possibly be explained by the unavailability of an institutional policy of continuous health education of nurse staff regarding these more specific topics concerning the critical care practice. 
Interestingly,it doubled to be $100.0 \%$ after the intervention with especial regards to timing of hand washing, care for continuously fed patient, frequency of tooth brushing and oral swabbing. This improvement indicates most probably the effectiveness of our intervention. This increase was in line with Meharali et al. (2011) Gatell et al. (2012)(18). Differently, Ferrazzano (2014) recorded no improvement in knowledge.

There was no significant correlation between the sociodemographic characteristics and the percentage of improvement in the total knowledge of the nurse staff of the ICU which could be explained by that the age, experience duration and infection control courses of them nearly showed no evident variability in distribution.The same result was found and reported by Gomes (2010) from Johannesburg and (Lamsoh et al., 2006) from Australia and different from that of Blot et al. (2007)

In conclusion, this study revealed that a relatively simple education program for implementation of guidelines recommended by Association for Professionals in Infection Control and Epidemiology (APIC) decreased the incidence rate of ventilator associated pneumonia (VAP) infection in the surgical intensive care unit by almost $25.7 \%$. It showed also marked improvement in the total satisfactory knowledge of both physicians and nurses in the studied ICU. From that, we recommend the following: 1.Continuous health education and training of ICU healthcare personnel regarding the knowledge, attitude and practice towards general infection control guidelines in the intensive care units, ventilator associated pneumonia (VAP) and the periodically updated evidence based guidelines for its prevention.2. Reevaluation of the intensive care unit policy to adopt the APIC prevention guidelines of VAP and other evidence based bundles for the prevention of different hospital acquired infections in the ICU.3. Standardize the case definition and the management protocol of VAP in all intensive care units.4. Enhancing appropriate use of antimicrobial treatment in the ICU setting to reduce antibiotic resistance and cost and to improve the patient's clinical response.5. Conduct more specific economic studies with longer follow up periods for evaluation of the economic cost and impact of VAP.6. Proper and full recording of different aspects of Zagazig hospital's costs for each department to facilitate economic or financial study analysis.

\section{Acknowledgement}

We wish to thank all patients and health care providers in the studied intensive care unit for their cooperation and help.

\section{References}

1. CDC (2015): Pneumonia (Ventilatorassociated (VAP) and non-ventilatorassociated Pneumonia (PNEU)). Device-associated Module PNEU/VAP.

2. El Nakera A, Meawed T, Aboserea M: Baseline surveillance Of Device Associated Infections (Dais) In A Surgical-Medical Intensive Care Unit At Zagazig University Hospital, Egypt. . Egypt. J. Microbiol 2012; 32(60).

3. Restrepo M, Anzueto A, Arrogliga A, Afessa B, Atkinson M, Schinner R, Ronald D, Bracken L and Kollef M: Economic burden of ventilatorassociated pneumonia based on total resource utilization. Infect Control Hosp Epidemiol. 2010;31:509-515

4. Sedwick M., Lance-Smith M., Reeder S. and Nardi J.: Using Evidence-Based 
Practice to Prevent VentilatorAssociated Pneumonia. Critical Care Nurse 2012; Vol 32, No. 4.

5. Matta: Prevention of Ventilation Associated Pneumonia, New Ideas and Better Results. J Pulm Respir Med 2014; $5: 1$

6. Keyt H, Faverio $\mathrm{P}$ and Restrepo M: Prevention of ventilator-associated pneumonia in the intensive care unit: A review of the clinically relevant recent advancements: Indian J Med Res 139, June 2014, pp 814-821.

7. Association for Professionals in Infection Control and Epidemiology (2009): Guide to the Elimination of Ventilator-Associated Pneumonia.http:// apic.org/ Professional-Practice /Implementation-guides

8. WHO (2009): WHO guidelines on hand hygiene in health care: A summary.Available from: http://www. whqlibdoc.who.int/hq/2009/WHO_IE $\mathrm{R}_{-}$

9. Wiech and Bayer (2012): Simple interventions for ventilator-associated pneumonia. Nursing CriticalCare 2012; 1 Volume 7, Number 3. Available at: www.nursing criticalcare.com

10. Pe'rez M, Muñoz P, Heras C, Sa'nchez G, Rello J, and Bouza E: Prevention of Ventilator-Associated Pneumonia: Can Knowledge and Clinical Practice Be Simply Assessed in a Large Institution? Respiratory Care 2013; VOL 58 NO 7

11. SPSS Inc. (2007): SPSS for Windows, Version 16.0. Chicago, SPSS Inc. Available from: http://www.unimuenster.de/imperia/m $\mathrm{d} /$ content/ziv/service/software/spss/han dbuecher/englisch/spss_brief_guide_1 6.0.pdf)

12. Epidemiological Information Package (EPi-Info) version 6.04.
13. Apisarnthanarak A, Pinitchai U, Thongphubeth K, Yuekyen C, Warren D

14. Zack J, Warachan B and Fraser V (2007): Effectiveness of an Educational Program to Reduce Ventilator-Associated Pneumonia in a Tertiary Care Center in Thailand: A 4Year Study. Clinical Infectious Diseases 2007; 45:704-11

15. Hawe C, Ellis K, Chris J, Cairns C and Longmate A (2009): Reduction of ventilator-associated pneumonia: active versus passive guideline implementation. Intensive Care Med 2009; 35:1180-1186. DOI 10.1007/s00134-009-1461-0

16. El-Kholy A, Saied T, Gaber M, Younan M, A. Haleim M, El-Sayed H, El-Karaksy H, Hafez Bazara'a $\mathrm{H}$ and Talaat m (2012): Device-associated nosocomial infection rates in intensive care units at Cairo University hospitals: First step toward initiating surveillance programs in a resourcelimited country. American Journal of Infection Control 2012; 40 e216-20 e217

17. Rosenthal VD, Guzman S and Crnich C (2006): Impact of an infection control program on rates of ventilatorassociated pneumonia in intensive care units in 2 Argentinean hospitals. Am J Infect Control2006; 34:58-63

18. Zack J, Garrison T, Trovillion E, Clinkscale D, Coopersmith C, Fraser V, Kollef M (2002): Effect of an education program aimed at reducing the occurrence of ventilator-associated pneumonia.Crit Care Med 2002; 30:2407-2412

19. Gatell M, Roig M, Vian O, Santín E, Duaso C, Moreno $I$ and Daunis $J$ (2012): Assessment of a training programme for the prevention of ventilator-associated pneumonia. 
Nursing in Critical Care 2012; Volume 17, Issue 6, pages 285-292.

20. Babcock H, E. Zack J, Garrison T, Trovillion E, Jones M, FraserV, and Kollef M (2004): An Educational Intervention to Reduce VentilatorAssociated Pneumonia in an Integrated Health System. A Comparison of Effects. CHEST 2004; 125:2224-2231

21. Baldwin and O'Neill (2015): A five year audit of ventilator-associated pneumonia: trends, organisms, antibiotic therapy and admission specialties. Intensive Care Medicine Experimental 2015; 3(Suppl 1):A701.

22. Apostolopoulou E, Raftopoulos V, Filntisis G, Kithreotis P, Stefanidis E,

23. Galanis P, and Veldekis D (2013): Surveillance Of Device-Associated Infection Rates And Mortality In 3 Greek Intensive Care Units. American Journal Of Critical Care 2013, Volume 22, No. 3.

24. Mehta Y, Gupta A, Todi S, et al. (2014): Guidelines for prevention of hospital acquired infections. Indian Journal of Critical Care Medicine ; Vol 18 Issue 3

25. Shakeel Amanullah Sh (2015): Ventilator-Associated

Pneumonia Overview of Nosocomial Pneumonias. Available at: http://emedicine.medscape.com/article/ 304836-overview\#a8

26. Elmenshawy AM, Elbadawy TH, Abu khaber H, Hafez SF, Fayed AM, Ibrahim EH (2014): The impact of VAP staff education on VAP morbidity and mortality in Alexandria University. Pulm Res Respir Med Open J.2014; 1(1): 32-45

27. Danchaivijitr S, Assanasen S, Apisarnthanarak A, Judaeng $\mathrm{T}$, Pumsuwan V (2005): Effect of an Education Program on the Prevention of Ventilator-Associated Pneumonia:
A Multicenter Study. J Med Assoc Thai 2005; 88 (Suppl 10): S36-41. Available at: http://www.medassocthai.org/journal

28. Arabi Y, Al-Shirawi N, Memish Z, Anzueto A (2008): Ventilatorassociated pneumonia in adults in developing countries: a systematic review. International Journal of Infectious Diseases 2008; 12，505512

29. Madani, N, Rosenthal V, Dendane T and Abidi K (2009): Health-care associated infections rates, length of stay, and bacterial resistance in an intensive care unit of Morocco: Findings of the International Nosocomial Infection Control Consortium (INICC). International Archives of Medicine 2009; 2: 29, 1-7

30. Joiner GA, Salisbury D and Bollin GE (1996): Utilizing quality assurance as a tool for reducing the risk of nosocomial ventilator associated pneumonia. Am J Med Qual 1996; 11:100-3.

31. Bayomi M (2012): Infection Control Performance at Dentist Clinic in Zagazig University Hospital: An Interventional Study. MD Thesis.Community medicine department. Faculty of Medicine Zagazig University.

32. El Nemr W, Fahmy H, Abed El Razek G and Abed El Salam N (2013): An interventional Study to Decrease Central Venous Catheter Related Blood Stream Infection in Intensive Care Units, Zagazig University Hospital. MD Thesis. Community medicine department. Faculty of Medicine Zagazig University.

33. Jansson M, Kääriäinen $M$ and Kyngäs H (2013): Effectiveness of educational programmes in preventing ventilatorassociated pneumonia: a systematic 
review. The journal of hospital infection 2013; Volume 84, Issue 3, Pages 206-214

34. Galal YS, Labib JR and Abouelhamd WA (2014): Impact of an infectioncontrol program on nurses' knowledge and attitude in pediatric intensive care units at Cairo University hospitals. J Egypt Public Health Assoc.2014; 89(1):22-8.

35. Eskander H, Morsy W, Elfeky H (2013): Intensive Care Nurses' Knowledge \& Practices regarding Infection Control Standard Precautions at a Selected Egyptian Cancer Hospital. Journal of Education and Practice 2013; Vol.4, No.19

36. Tolentino DelosReyes A, Ruppert S and Shiao P (2007): Evidence-Based Practice: Use of the Ventilator Bundle to Prevent Ventilator-Associated Pneumonia. Am J Crit Care January 2007 vol. 16 no. 1 20-27

37. Meherali SM, Parpio Y, Ali TS and Javed F (2011): Nurses' knowledge of evidence-based guidelines for prevention of ventilatorassociated pneumonia in criticalcare areas: a pre and post test design. J Ayub Med Coll Abbottabad 2011; 23(1):146-9.

38. Ferrazzano D (2014): Preventing Ventilator-Associated Pneumonia: Educating Emergency Room Nurses. Master of Science in Nursing. Paper 40.

39. Gomes V (2010): Knowledge Of Intensive Care Nurses On Evidence Based Guidelines For Prevention Of Ventilator Associated Pneumonia. A Master research report of Science in Nursing. Faculty of Health Sciences, University of the Witwatersrand, Johannesburg.

40. LamSoh K, Koziol-McLain J, Wilson J, \& Geok Soh K (2007): Critical care nurses' knowledge in preventing nosocomial pneumonia. Australian Journal of Advanced Nursing 2007, 24(3), 19-25.

41. Blot S, Lisboa T and Angles R (2011): Prevention of VAP: Is Zero Rate Possible? Clin Chest Med 2011; 32: 591-599.

\section{How to cite this article:}

Amany Rashad Abo Elseoud, Mona Mostafa AboSerea, Ghada Mohammed Abed El Razek and Safa Abdul Monaem Hussein. 2016. An interventional study for reducing Ventilator Associated Pneumonia in Surgical Intensive Care Unit, Zagazig University Hospitals. Int.J.Curr.Microbiol.App.Sci. 5(2): 202-214. doi: http://dx.doi.org/10.20546/ijcmas.2016.502.023 